\title{
LETTER
}

\section{Physical Map of Human 6p212-6p213: Region Flanking the Centromeric End of the Major Histocompatibility Complex}

\section{Nicos Tripodis, ${ }^{1}$ Ruth Mason, ${ }^{1}$ Sean J. Humphray, ${ }^{2}$ Angela F. Davies, ${ }^{1}$ Jethro A. Herberg, ${ }^{3}$ John Trowsdale, ${ }^{3,6}$ Dean Nizetic, ${ }^{4}$ Gabriele Senger, ${ }^{5}$ and Jiannis Ragoussis ${ }^{1,7}$}

${ }^{1}$ Division of Medical and Molecular Genetics, United Medical and Dental School of Guy's and St. Thomas', Guy's Hospital, London SE1 9RT, UK; ${ }^{2}$ The Sanger Centre, Wellcome Trust Genome Campus, Hinxton, Cambridge CB10 1SA, UK; ${ }^{3}$ Imperial Cancer Research Foundation (ICRF) Laboratories, London WC2A 3PX, UK; ${ }^{4}$ Centre for Applied Molecular Biology, University of London, School of Pharmacy, London WC1N IAX, UK; ${ }^{5}$ Institut für Humangenetik und Anthropologie, D-07740 Jena, Germany; ${ }^{6}$ Department of Pathology, University of Cambridge, Cambridge CB2 1QP, UK

We have physically mapped and cloned a 2.5-M chromosomal segment flanking the centromeric end of the major histocompatibility complex (M HC). We characterized in detail 27 YACs, 144 cosmids, 51 PACs, and 5 $B A C S$, which will facilitate the complete genomic sequencing of this region of chromosome 6 . The contig contains the genes encoding CSBP, p21, HSU 09564 serine kinase, ZNF76, TCP- 11, RPS1D, HM GI(Y), BA K, and the human homolog of Tctex-7 (HSET). The GLO1 gene was mapped further centromeric in the 6p212-6p211 region toward TCTE- 1 The gene order of the GLO 1- HMGI(Y) segment in respect to the centromere is similar to the gene order in the mouse t-chromosome distal inversion, indicating that there is conservation in gene content but not gene order between humans and mice in this region. The close linkage of the BAK and CSBP genes to the MHC is of interest because of their possible involvement in autoimmune disease.

The 2.5- $\mathrm{Mb}$ chromosomal segment flanking the centromeric end of the major histocompatibility complex (MHC) spans the boundary of the $6 \mathrm{p} 21.2$ (Giemsa dark) and 6p21.3 (Giemsa light) bands. This segment is of interest because of the association of the MHC with diseases, particularly of autoimmune etiology and the synteny to the mouse tcomplex distal inversion on chromosome 17 (Hamvas et al. 1996). The conservation between the 4-Mb human $\mathrm{MHC}$ and the mouse $\mathrm{H} 2$ complex is well documented (Hanson and Trowsdale 1991; Amadou et al. 1995), but for the region centromeric to the MHC, it is not well established.

The mouse t-complex is an intensively studied region containing genes, which, when mutated or rearranged, cause a number of effects including embryonic lethality, male sterility, recombination suppression, and transmission ratio distortion (Silver 1993b; Foreijt et al. 1994). A part of this complex, within the distal inversion extending from the

${ }^{7}$ Corresponding author.

E-MAIL i.ragoussis@umds.ac.uk; FAX 44-171-955-4444. mouse $\mathrm{H}$ mgi (y) gene to the $\mathrm{H} 2-\mathrm{K}$ region, contains a number of testis-expressed genes (Abe et al. 1988; Yeom et al. 1992). Testis-expressed sequences have been previously identified centromeric to the MHC (Ragoussis et al. 1992).

In humans, this region harbors a gene involved in retinitis pigmentosa (ArP14) (Shugart et al. 1995) whereas chromosomal rearrangements with breakpoints within the region are associated with neoplasia (Johansson et al. 1993; Nilbert et al. 1995; Xiao et al. 1997).

To investigate the relationship of this human segment to the mouse t-complex distal inversion, we have assembled YAC and bacterial clone contigs and mapped sequences with known homology between mice and humans. We screened a variety of genomic libraries in different cloning vectors to obtain clones, and we used both fingerprinting- and hybridization-based approaches to construct contigs. The resulting contigs have enabled the construction of transcript maps and are a first step toward construction of sequence-ready bacterial clone contigs. 
TRIPODISETAL.

\section{RESULTS}

Construction of a YA C Contig

As a first step toward cloning the region, we constructed a YAC contig. This was completed by screening the CEPH, ICRF, and ICI libraries with the markers D6S273, D6S291, D6S439, D6S29, HMGI(Y), TCTE-1, Motilin, and GLO1 by PCR and with PIM 1 and HKE3 probes by hybridization. In parallel, the Genèthon Quickmap programs were used to identify 175 clones from the CEPH YAC library that potentially linked the D6S291 marker to D6S273. Additional markers were used as released by the Whitehead database and by Sheffield et al. (1996). The results of these PCR- and hybridization-based screenings are shown in Figure 1A.

Additional clones were isolated with probes mapping further centromeric. These clones were with TCTE-1, AM 150a5, AM 149e2, AM 149e3 (ICRF library); with GLO1, 807g9 and 816c12 (CEPH library); with PIM 1, 756g4 (CEPH library) in addition to $4 \mathrm{D} 3$ and 5.2 containing PIM 1 (described in Ragoussis et al. 1992). A clone positive for the Motilin PCR product, 648c8 (CEPH library) was isolated; however, subsequent mapping by FISH did not allow a localization on $6 \mathrm{p}$.

No positives were identified in any of the three YAC libraries with the probe for the BAK gene. When high-density filters containing all isolated clones were screened, the ICl clone RA15B12d (isolated with the D6S29 marker) was positive and was positioned on the map retrospectively (see Fig. 4, below). The same YAC was positive with cosmids containing the BAK gene, but it does not contain the entire coding sequence, as shown by PCR analysis (J.A. Herberg, unpubl.). It is possible that even very low expression of this gene is lethal to yeast (Ink et al. 1997).

To establish that the YAC clones were derived from chromosome $6 p$, several overlapping clones were localized on chromosome 6 by FISH. All YACs that gave a signal on $6 p$ mapped in the 6p21.2$6 p 21.3$ interval (see FISH mapping, below), except YAC 816c12, containing GLO1, which was localized in the telomeric part of the $6 \mathrm{p} 21.1$ band. To establish the position of GLO1 in relationship to the TCTE-1 gene, another human homolog of a mouse t-complex gene, which is reported to map within the 6p21.1 chromosomal band at the marker D6S271, we mapped two YAC clones containing TCTE-1 (AM149e2 and AM150a5) within 6p21.1, proximal to $816 \mathrm{c} 12$. This indicates that GLO1 maps distal to TCTE-1 in humans. These data agree with data produced by the Whitehead institute, where
YAC $816 \mathrm{c} 12$ is positioned in a contig distal to YACs containing D6S271. The YACs 812e10 and 923g9 containing D6S1011 were mapped at the centromeric end of the $6 p 21.1$ band, close to $6 p 12$. These YACs are reported as containing the marker D6S438 by the Whitehead database, the position of which agrees with this localization.

The YACs $683 \mathrm{e} 10$ and $649 \mathrm{f} 11$ failed to produce a signal on $6 p$ but they were positioned on the map (Fig. 1) according to marker content and subsequent cosmid hybridization results. Finally, two YACs, 880d5 and RA34I9, containing D6S273 were mapped within the class III region because they hybridized to probes for HSP70.

\section{Construction of Cosmid Pockets}

A backbone of YAC clones was used to screen the ICRF chromosome 6-specific cosmid library. YACs 879g7, 758c5, 800e3, 808h5, 919d11, 769f10, 9.2, $62 \mathrm{~g} 5,778 \mathrm{~d} 11$, and $649 \mathrm{f} 11$ (Fig. 1A) were used to sel ect 802 cosmids in total. The cosmids were picked into 96-well plates and spotted at high density onto filters. All of the YACs in Figure $1 \mathrm{~A}$ were used to rescreen the cosmids and construct pockets. In addition, the YAC clone 9.2 was subcloned into the Supercos cosmid vector to enrich for clones mapping to the TCP-11 region. Sixty-five clones were picked and used along with the cosmids resulting from the hybridization screen.

\section{Construction of Cosmid Contigs}

The construction of cosmid contigs was performed by use of hybridization-based approaches: First, selected cosmids from individual pockets were used to hybridize the YAC filters and confirm the position of the particular cosmid and pocket. In all, 105 cosmids were used as hybridization probes on the YAC and cosmid filters. In addition, 59 probes derived from cosmid internal or end fragments and YAC end fragments were used. As a result, 346 cosmids were isolated from the chromsome 6-specific cosmid library, of which 190 were confidently assigned to contigs and mapped to defined positions.

Individual probes corresponding to known genes were also used to identify positive clones. Thus cosmids hybridizing to human KE3, mouse Tctex-7, BAK, TCP-11, ZNF76, and p21 (W AF-1) were initially identified within the isolated cosmids. The PIM - 1 probefailed to identify any cosmids from the chromosome 6 library. Therefore the YAC $725 \mathrm{~g} 4$ was used to isolate a number clones, two of which, 

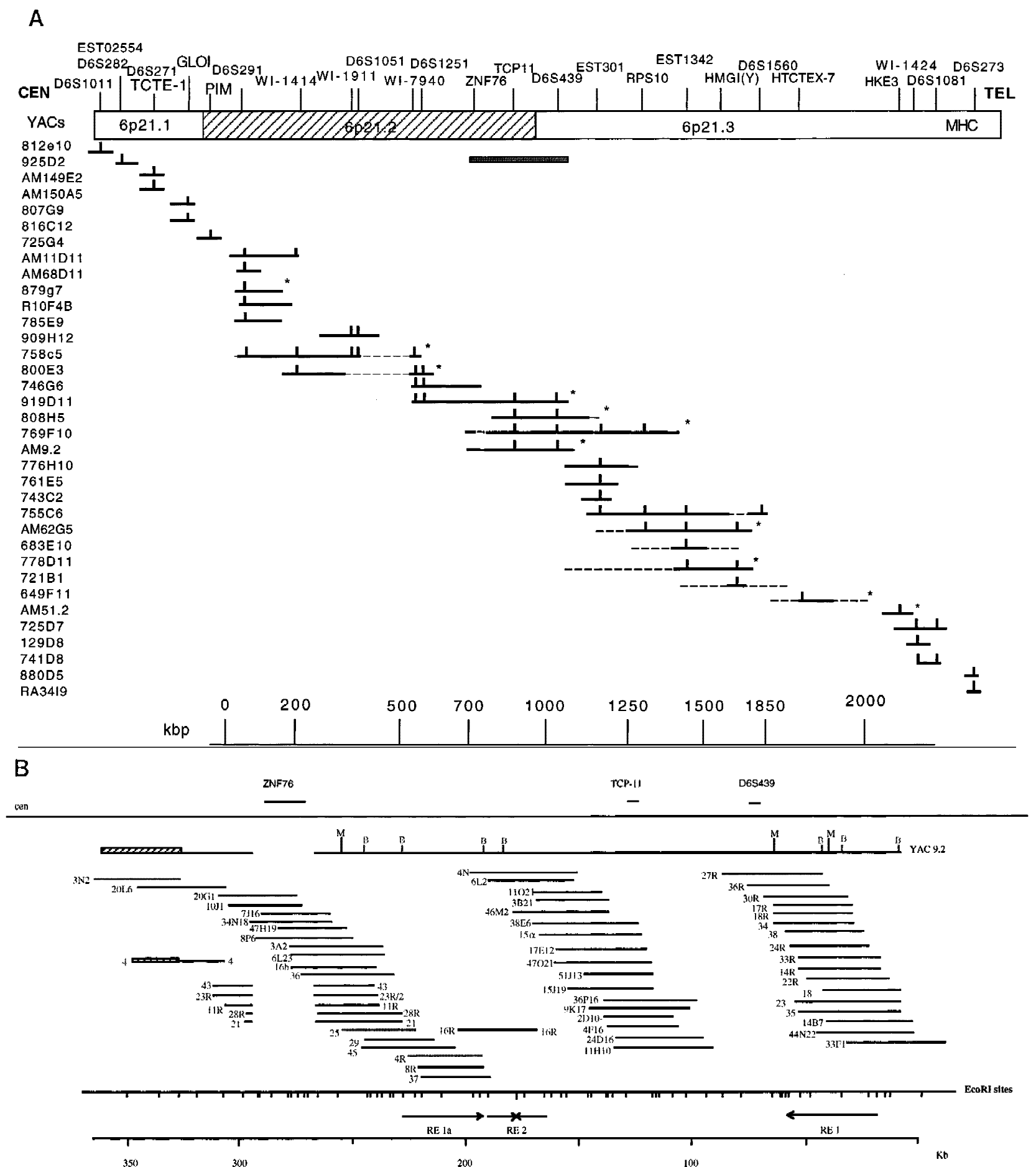

Figure 1 (A) YAC contig covering the 6p21.2-21.3 region. YACs from three libraries are listed to the left and markers at the top. The YACs and markers in 6p21.1 are shown ordered toward the centromere. Vertical bars indicate the presence of markers in the particular clone and thin interrupted lines indicate chimeric parts. An asterisk indicates that the clone has been used to isolate the cosmids shown in B and Fig. 4. The shaded bar under the ZN F76-D6S439 region indicates the finely mapped segment shown in B. (B) Restriction map of the 350-kb ZN F76TCP-11 region. The positions of the two genes and D6S439 are shown above, and the position of Mlul and BssHII sites as determined by PFGE analysis of YAC 9.2 and digestion of cosmids are below. Cosmids are derived from the chromosome 6 library or by subcloning the YAC 9.2. The left end of the YAC is chimeric to $6 \mathrm{p} 12$ (hatched bar) and the same was found for the subcloned cosmid 4 that hybridizes by FISH to $6 \mathrm{p} 21$ and $6 \mathrm{p} 21.2$. The region deleted in YAC 9.2 is indicated by a gap in cosmids 43,23R/2,11R, 28R, and 21 (see also Fig. 3). The EcoR map derived from the cosmids and the position of the repeated elements with relative orientation are presented at the bottom. 
40D7 and 49012 hybridized back to the YAC and were used for FISH mapping as representatives of this locus.

To aid the contig construction in the ZNF76RSP10 region, the YAC $769 f 10$ was fragmented by use of the vector pBCL8.1. Ninety-six products with a range of 100-800 kb were sized by PFGE and used to position probes from the region covered by YAC 9.2. Cosmids/probes were hybridized to gridded YAC fragmentation products, and the results were used to orient the cosmid contig encompassing YAC 9.2 relative to the other contigs (not shown and Fig. 4 , below). The results also established the order of markers in the region (Fig. 4, below).

The presence of the CSBP gene was detected by PCR. Probes for the mouse Tctex-11 and Tctex-3 genes were also used, but these failed to detect any positives in both our selection of cosmids and the entire chromosome 6 library filters. The cosmid contigs were verified subsequently by double-digest fingerprinting after micropreparation in a 96-well format. By combining of the hybridization and fingerprinting data, nine contigs were constructed. The order of these contigs was determined not only according to their hybridization pattern on gridded YACs but also by elongated chromatin fiber (ECF) and interphase FISH techniques (see below). Further evidence of location and order was obtained by PFGE on genomic DNA.

\section{BA C/ PA C Screening and Contig Construction}

To extend the contigs and to close gaps between the cosmids, the human BAC library was screened with end probes from cosmid 32022, resulting in the isolation of three BAC clones. One PAC clone was isolated by PCR with the marker WI-7940 and end probes from this PAC identified an additional three BAC clones. Another PAC clone was isolated by PCR with marker D6S1560 and in parallel by hybridization with the coding region of BAK. Whole cosmids and end probes were used for isolating PAC clones by hybridization to increase the depth of the contigs. Twenty cosmids were hybridized to the PAC library in two sets of ten. Ninety-one PACs were identified as positive. PAC/BAC walking with the use of end probes produced fifteen additional PAC clones.

The positioning of the BAC and PAC clones was verified by PCR with the relevant markers at each position and secondary screenings when appropriate. The overlaps of PAC and BAC clones were verified by hybridizations and fingerprinting, and the size of all key clones was determined by PFGE fol- lowing Notl digestion. The fingerprinting patterns of the PACs and BACs were compared to the patterns obtained from the cosmids, leading to the construction of contigs that incorporated all types of clones.

In total, 82 clones were positioned, forming contigs that overlap with and extend the cosmid contigs, 50 of which are presented on the map in Figure 4 (below). Examples of these contigs can be seen at the Sanger Centre's chromosome 6 database (http://www.sanger.ac.uk/HGP/Chr6/) as contig 2 (around D6S291), contig 8 (containing p21), contig 3 (WI-7940), and contig 6 (D6S439).

Detailed EcoRI, BssHII, and MluI Map of the YA C 9.2 Region

The region contained within YAC 9.2 was analyzed further by detailed hybridization screening with a series of cosmid fragments resulting from EcoRI digestion of the subcloned cosmids and end fragments of the chromosome 6 cosmids. Partial digestion with EcoRI of two subcloned cosmids was also performed, and the EcoRI digestion pattern of all the cosmids coming from the region was analyzed manually. All cosmids were investigated further for the presence of BssHII and Mlul sites, which were assigned according to the partial digestion patterns of YAC 9.2. All the restriction sites were ordered (Fig. 1B), revealing the existence of two locations with multiple BssHII restriction sites, suggesting possible $\mathrm{CpG}$ islands. The detailed analysis also revealed an internal deletion of YAC 9.2, which was carried over to the subcloned cosmids. The 26-kb deletion was bridged by use of the chromosome 6 cosmids. Within this deleted segment lies the coding region of ZNF76. The deletion is also present in all the overlapping YACs that were screened from the region.

Another feature of this region is the existence of a specific repetitive element that extends over $33 \mathrm{~kb}$. The element contains multiple EcoRI and BamHI fragments that cross-hybridize to one another. The repetitive element could not be suppressed by competition with total human DNA. The repeats contained BssHII and Mlul restriction sites at varying locations, facilitating the separation and ordering of the EcoRI fragments. The repetitive element is present three times in the YAC 9.2 region, twice in reverse orientation and once in a combined form (Fig. 1B.).

The detailed analysis of the region allowed the positioning of TCP-11, ZNF76, and D6S439 within 
specific EcoRI fragments and the generation of a $350-\mathrm{kb}$ restriction map of the region.

FISH A nalysis and Long-Range A nalysis by PFGE

The YAC clones that were used to assemble the contigs were mapped by FISH on metaphase chromosomes to 6p21.2-6p21.3. YAC 880d5 gave signals on $6 p 21.3,3 p 21.3$, and 14q22; RA3419 localized on $6 \mathrm{p} 21.31 ; 725 \mathrm{~d} 7$ localized on $6 \mathrm{p} 21.3$, but also on 4q32, and 14q12-q13; and YAC 769f10 localized on 6p21.3. AM 62g5, 879g7, and 756g4 were mapped to 6p21.2-p21.3 and 778d11 and RA10F4B to 6p21.2. $778 d 11$ gave an additional signal on 11q24 and $879 \mathrm{G} 7$ on 2 2q32. YAC $816 \mathrm{c} 12$ was mapped to the distal part of 6p21.1, while AM 149e2, AM 150a5, and $925 \mathrm{~d} 2$ mapped to $6 \mathrm{p} 21.1$ and $812 \mathrm{e} 10$ at the centromeric end of 6p21.1. The YACs $649 f 11$ and $683 e 10$ gave signals only on $4 q 25$ and $4 q 27$, respectively, suggesting that most of their insert is not derived from chromosome 6.

The BAC clones 6B8, 64E9, and 121L5 were localized on $6 \mathrm{p} 21.2$ whereas BAC $133 \mathrm{E} 7$ localized on $6 p 21.2-p 21.3$. The PACs 225D9 and 247M 13 were localized on 6p21.2 and 6p21.2-p21.3, respectively. The following cosmids were localized on 6p21.3: 7A19, 7B18, 49H12, 39E3. The cosmids 7C15, 1J2, 33F1, 4R, 30R, 9G11 and 20L4 were localized on 6p21.2-p21.3. Cosmid 4, a subcl one of YAC9.2 containing one of the YAC ends, was localized on $6 p 21.2$ and 6p12.2-p12.3, confirming the chimeric nature of the YAC, but no other subclone hybrid- ized to 6p12.2-p12.3. The cosmids 3N2, 33G5, 48N23, 36E22, 37P17, 23P5, 4619, 16P13, and 11D11 were localized on 6p21.2. The cosmids 40D7 and 49012 , isolated by use of the YAC 725G4, were localized on 6p21.2.

The order of cosmid, PAC, BAC, or YAC clone trios was determined in interphase nuclei. Orders established were: 45P17-PAC 225D9-48N23 (ratio 36:6); 33F1-7K5-12B11 (ratio 30:14); 33F1-40E1539E3 (ratio 21:5); and 40E15-7K5-39E3 (ratio 21:8). The cosmid 1j20, found to map within the MHC class III region, was used to establish the order of clones in respect to the $\mathrm{MHC}$. This was as follows: 1J2-39E3-1J20 (ratio 10:3); and 51B16-7B18-1J20 (ratio 12:2).

The distance between individual clones within a range of 100-1000 kb was established by FISH on cal ibrated interphase nuclei. These were as follows: 46K17-87 \pm 125 kb-1J2-390 \pm 22 kb-7C15; 7B18$185 \pm 35 \mathrm{~kb}-51 \mathrm{~B} 16-250 \pm 35 \mathrm{~kb}-7 \mathrm{~K} 5 ; 20 \mathrm{G} 1-$ $323 \pm 35 \mathrm{~kb}-33 \mathrm{~F} 1-321 \pm 46 \mathrm{~kb}-14 \mathrm{I} 20 ; 18 \mathrm{H} 1-$ $580 \pm 65 \mathrm{~kb}-48 \mathrm{~N} 23 \leqslant 50 \mathrm{~kb}-3 \mathrm{~N} 2$; and 46I9$100 \pm 35$ kb-45P17-320 \pm 40 kb-3N2 (see Fig. 2).

For higher resolution (10- to 400-kb range), chromatin fibers were used, which also confirmed the overlap between clones, as well as the distances established by analysis of the EcoRI restriction pattern of cosmids. The distances were defined as cosmids, reflecting the average length of signal on the ECF when a single cosmid was used as a probe. The results were 9G11-2/3cos-16P13; 20L4-2/3cos$52 \mathrm{~N} 2 \geqslant 2$ cos-9G11; 20L4-5.8cos-9G11; 23P52cos-36E22-45P17; 23P3-1.3cos-36E22-45P17;

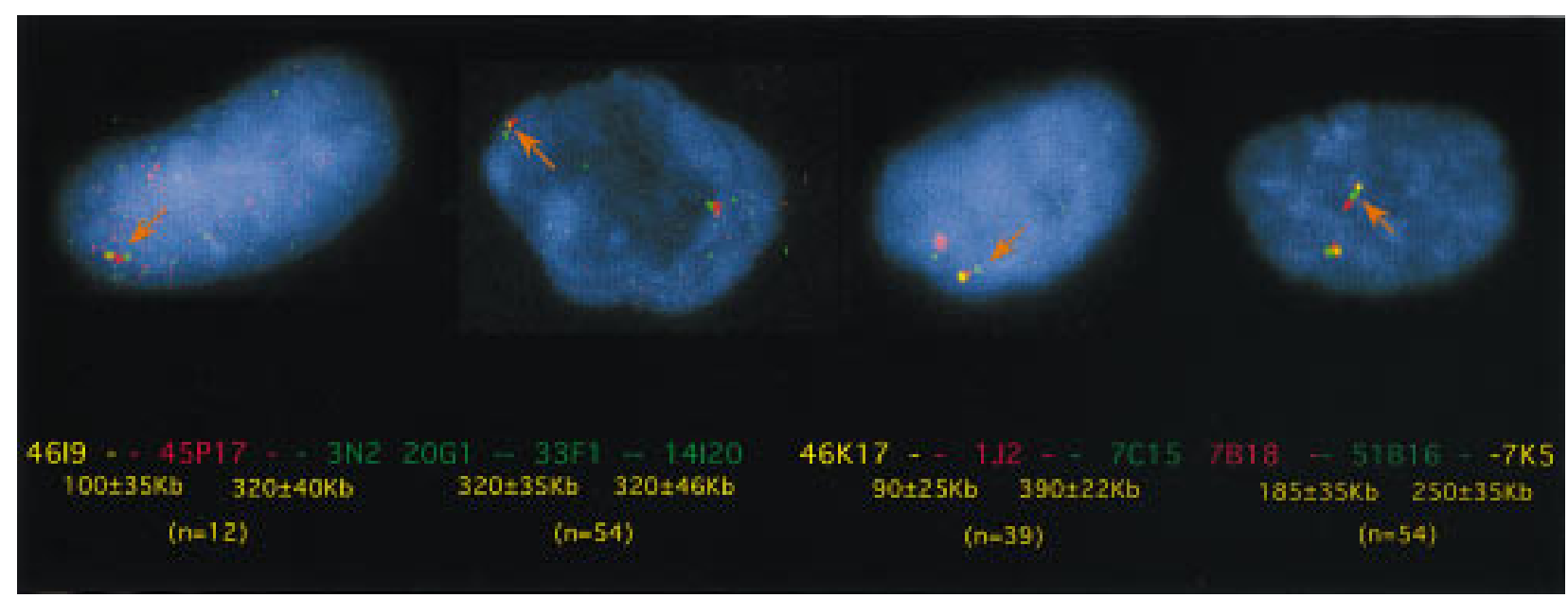

Figure 2 Determination of cosmid clone order and distances by interphase FISH across the 6p21.2-6p21.3 region. From left to right (combinations of three clones): 20G1 (digoxigenin labeled), 33F1 (double labeled), and 14120 (biotin labeled); 46K17 (double labeled), 1J2 (digoxigenin labeled), and 7C15 (biotin labeled); 7B18 (digoxigenin labeled), 51B16 (biotin labeled), and 7K5 (double labeled); and 4619 (double labeled), 45P17 (digoxigenin labeled), and 3N2 (biotin labeled). In brackets below is the number of nuclei measured. 


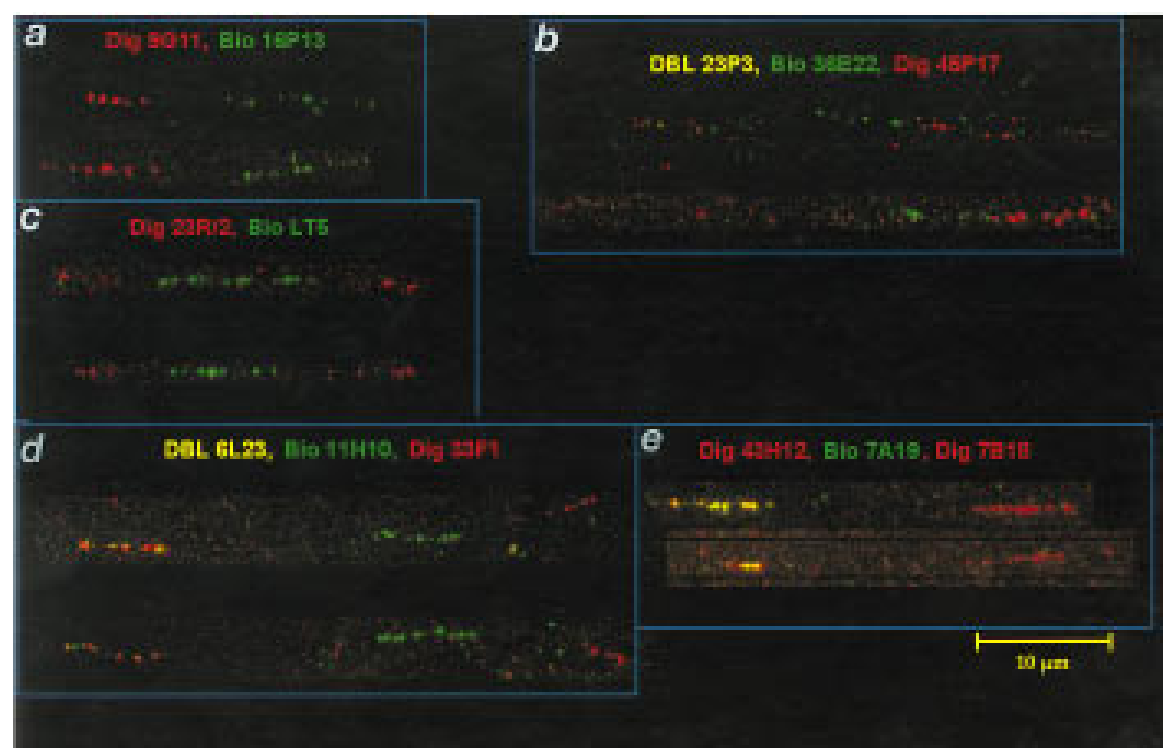

Figure 3 ECF-FISH analysis of cosmids across the 6p21.2-6p21.3 region. From centromere to telomere: (a) The distance between cosmids 9G11 and 16P13 in the D6S291 region is about one-half cosmid length. (b) Ordering the cosmids 23P3-36E22-45P17. (c) Visualization of the deletion in YAC 9.2 that encompasses ZNF76. The cosmid LT-5 containing ZNF76 is flanked by the subcloned cosmid 23R/2. (d) Ordering of cosmids in the region ZNF76-TCP-11. (e) The cosmid $49 \mathrm{H} 12$ (right) containing HTCTEX-7 is two cosmid lengths apart from the overlapping cosmids 7A19 and 7B18, which contain HKE3.

full agreement with the position given in their paper.

Mapping of Genes and ESTs within the Contigs

The cDNAs corresponding to the BAK gene, the $\mathrm{HMGI}(\mathrm{Y})$ gene, HTCTEX-7, EST 1342, RPS10, the serine kinase HSU 09564(WI-7940), TCP-11, ZNF76, p21, EST T54911, and EST R12494 were all mapped within cosmid, PAC, or BAC clones (see Fig. 4). EST 301 was present on YAC 769f10, but no cosmids were identified by PCR. The EST is highly similar to RPS10, (in EST 301 the ORF for the RPS10 protein is disrupted) and indeed hybridizes to cosmids containing RPS10. Because RPS10 is detected by PCR with primers derived from intronic sequences, in contrast to EST 301 , where the primers are derived from cDNA sequences, it

$18 \mathrm{H} 1 \geqslant 2.2$ cos-33G5-48N23; 6L23-2cos- $11 \mathrm{H} 10-$ 1.5cos-33F1; and 7B18-7A19-1.6cos-49H12 (see Fig. 3). The same technique all owed the demonstration of the internal deletion of YAC 9.2. In this case, we compared the subcloned cosmid $23 \mathrm{R} / 2$ and cosmid LT-5, which contains the coding region of ZNF76. This comparison revealed that $\sim 30 \mathrm{~kb}$ around the ZNF76 region was deleted in YAC 9.2 (see Fig. 3).

Further confirmation of distances and order was derived from PFGE analysis with probes derived from the HKE3, HTCTEX-7, TCP-11, ZNF76, CSBP, $\mathrm{HMGI}(\mathrm{Y}), \mathrm{BAK}$, and $\mathrm{p} 21$ regions (data not shown). In particular, the position of the cosmid contig containing HTCTEX-7 was established by the detection of a 440-kb Notl and a 230-kb M lul fragment that al so hybridized with the probe for HKE3. This result is consistent with Notl and M lul fragments that extend toward the centromere encompassing RING1, RING2, and HKE3 (Hanson and Trowsdale 1991). The distance between HKE3 and Col11 $\alpha 2$ is $100 \mathrm{~kb}$. In line with the distances obtained by FISH, the detection of these fragments positioned HTCTEX-7 proximal to HKE3 and within $130 \mathrm{~kb}$ of it. The human homolog of Tctex-7 (HTCTEX-7) was identified as HSET by (Ando et al. 1994), and our data are in is likely that this EST corresponds to a RPS10 pseudogene. The position for this pseudogene, was established by PCR screening of the YAC fragmentation products of 769f10. All products with a size of $250 \mathrm{~kb}$ and above contained EST 301, whereas products with a size of $100 \mathrm{~kb}$ and above contained RPS10. The D6S439 marker was present in products of $550 \mathrm{~kb}$ and longer as well as within the contig (see Fig. 4). These data establish that EST 301 maps between RPS10 and D6S439, $150 \mathrm{~kb}$ centromeric to the RPS10 gene.

The marker WI-7940, corresponding to the mRNA for serine kinase HSU09564, was positioned centromeric to ZNF76 on PACs 247M 13, 51008, and 526M 12. The p21 (W AF-1) gene was mapped to cosmids 52N2 ( $5^{\prime}$ end) and 18D21 ( $3^{\prime}$ end) by PCR and hybridizes together with the markers WI-10190, WI-7311, and the EST T54911, all of which correspond to the p21 gene.

These results, combined with the location of markers (Fig. 4) establish the following order: CenD6S291-CSBP-WI-6620-NIB1566 and R12494D6S1051/p21-5'-WI-10190/WI-71311/p21-3'/ T54911-WI-7940/HSU 09564-ZNF 76-TCP-11D6S439-EST 301-RPS10-EST 1342-HMGI(Y)D6S29-BAK-D6S1560-HTCTEX-7(H SET)-HKE-3- 


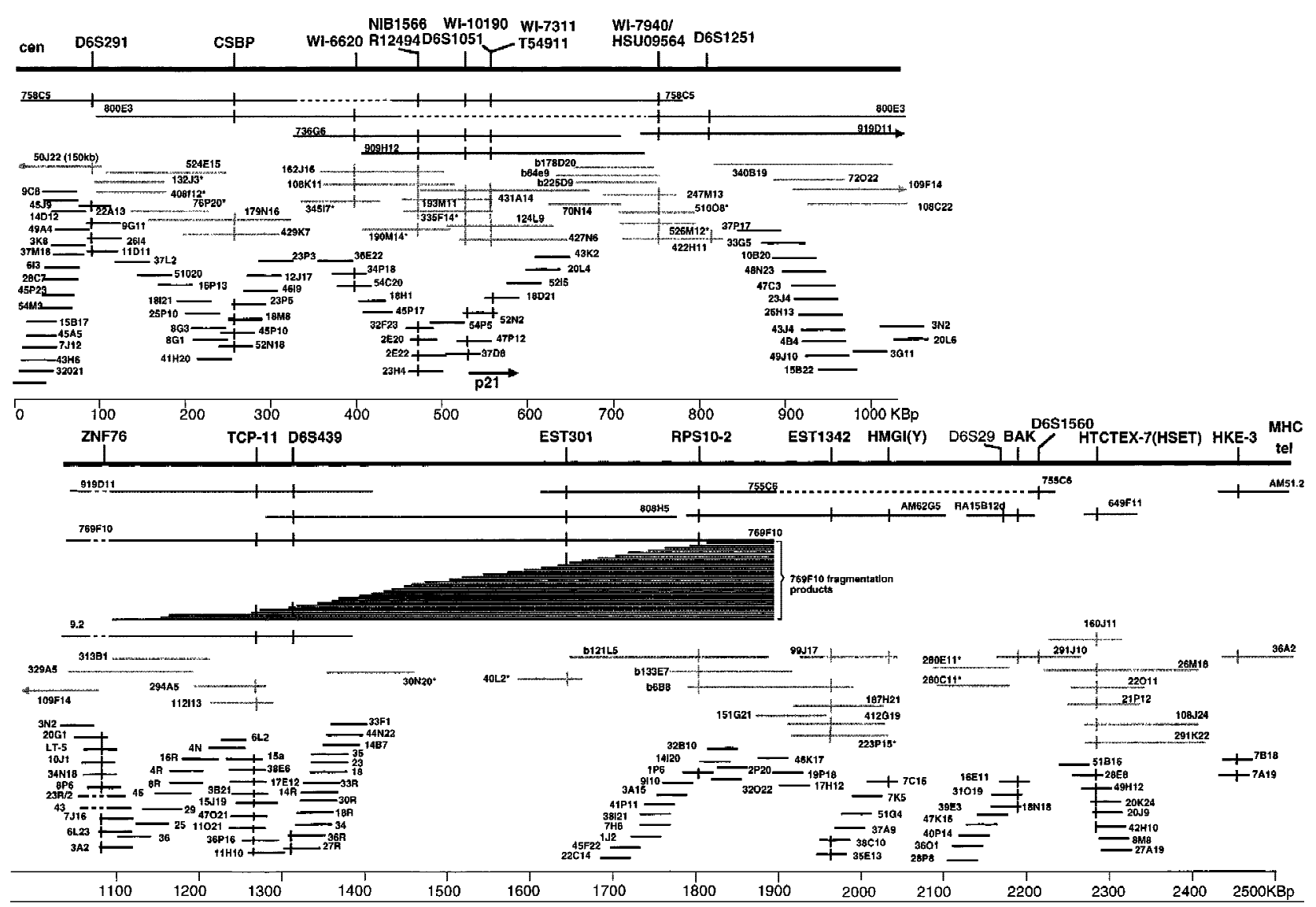

Figure 4 Composite map of $2.5 \mathrm{Mb}$ centromeric to the MHC. The backbone of YAC clones is shown at the top, underneath PAC and BAC clones (shaded) and cosmid clones (black). The extent of the bars indicates the length of the clones as established by PFGE and restriction enzyme digestion. Asterisks beside the clone address indicates that the size of the clone has not been determined. Markers are at the top and vertical bars on clones indicate positive screening results. The position of the D6S29 marker has not been confirmed in other clones except RA15B12d.

MHC. The distances between markers and genes were al so determined (Fig. 4). Other ESTs tested but not found in the $Y A C /$ bacterial clone contigs were D6S1535E, D6F304S2E, D6F310S2E (reported to map on chromosome 6), EST 02289, EST 02554 as well as the markers FB2A D6S394-D6S389 and D6S329. Of these, EST 02554 was detected on YAC $925 \mathrm{~d} 2$ reported to be part of a contig around the D6S271 marker at 6p21.1.

We were not able to locate the PIM 1 gene accurately. The CEPH YAC $725 g 4$ isolated with the PIM 1 cDNA has been mapped to 6p21.2-21.3 on metaphase chromosomes. By comparison, the ICRFYACs that were isolated previously were mapped to $6 p 21.2$ by the same technique. There were no Whitehead data about this YAC in the database release of 6/9/96. Cosmids isolated from the chromosome 6 library with YAC 725g4 were mapped back to the YAC and to chromosome 6p21.2 (clone 40D7, 49O12). Interphase FISH mapping of 40D7 in combination with cosmids from the D6S291D6S439 interval did not yield any consistent order or distances. We have observed inconsistent distance and orders in cases where the distances be tween the probes was $>600 \mathrm{~kb}$. This observation would indicate that PIM 1 is not within the $2.5-\mathrm{Mb}$ region presented here. This hypothesis was supported by PFGE results, where thebands hybridizing to PIM 1 did not correspond. The EST map data position PIM 1 in the D6S291-D6S1641bin (the next marker toward the centromere), and, therefore, in combination with our data, the most likely location for PIM 1 would be centromeric of D6S291 within $6 \mathrm{p} 21.2$.

\section{DISCUSSIO N}

We have constructed a physical map by generating YAC, PAC, BAC, and cosmid contigs covering the region between the D6S291 marker and the MHC, 
crossing the $6 \mathrm{p} 21.2$ and $6 \mathrm{p} 21.3$ chromosomal bands. The contigs have been generated by use of a combination of techniques. Initial assembly was performed by hybridization of YAC-derived probes to organized library filters followed by hybridization of whole cosmids or probes derived from them to cosmid and YAC filters. After contig assembly, the position of the clones within the contigs was confirmed by fingerprinting. In general there was overall agreement between the data obtained with both techniques.

The $2500 \mathrm{~kb}$ are covered in three bacterial clone contigs. One contig, extending from PAC 50J22 to $30 \mathrm{~N} 20$ and covering $1500 \mathrm{~kb}$ from D6S291 to D6S439 inclusive, a second covering $400 \mathrm{~kb}$ from PAC 40L2 to cosmid 7C15 containing the markers EST 301 to $\mathrm{HM} \mathrm{GI}(\mathrm{Y})$ and one covering $350-400 \mathrm{~kb}$ from PAC280E11 to PAC26M18, containing BAK and HTCTEX-7. The gaps between these contigs reflect mainly, on the one hand, regions not represented in the cosmid library, as the cosmid contigs are the result of exhaustive walking steps, and, on the other hand, the paucity of additional markers available at the time, that could enable a direct screen of genomic libraries. Closing the gaps through multiple walking steps in the PAC library has not been completed because of time constraints. However, PFGE and high resolution FISH mapping data confirm that the gap between the cosmids 33F1 and $22 \mathrm{C} 14$ in the D6S439-EST 301 region is $200 \mathrm{~kb}$, part of which is covered with the PACs 30N 20 and $40 \mathrm{~L} 2$. The same techniques suggest that the gap between cosmid 7C15 and the PACs 280E11/280C11 is either not existing or below $10 \mathrm{~kb}$, and the gap between PAC 291K22 and the cosmids 7B18/7A19 is on the order of 5-20 kb (see Fig. 4).

The contigs consist of 27 YACs, 144 cosmids, 51 $\mathrm{PAC}$, and $5 \mathrm{BAC}$ clones covering $2.5 \mathrm{Mb}$ centromeric to the MHC. This region contains genes that have been implicated in the development of neoplasia, such as p21 and $\mathrm{HMGI}(\mathrm{Y})$ (Fedele et al. 1996). Of particular interest is the finding that $6 \mathrm{p} 21$ rearrangements involve the region around the $\mathrm{HMGI}(\mathrm{Y})$ gene (Kazmierczak et al. 1996). Apart from affecting the expression of the $\mathrm{HMGI}(\mathrm{Y})$ gene, these rearrangements may also influence the expression of other genes in the vicinity, such as BAK. The BAK gene product is a potent inducer of apoptosis and shows widespread expression in human tissues. It is a homolog of the $\mathrm{BCl} 2$ gene, and transgenic mice expressing the human $\mathrm{BCl} 2$ gene constitute a model for systemic autoimmune disease resembling the human disorder systemic lupus erythematosus (Strasser et al. 1991).
In humans, the genotype of the MHC is the strongest genetic determinant for many autoimmune diseases, and BAK maps just $300 \mathrm{~kb}$ centromeric to the MHC class II region. Another gene of immunological interest in the region is the gene encoding CSBP, a protein kinase activated by mitogens and stress stimuli, which plays a critical role in cytokine production (IL-1, TNF) (Lee et al. 1994). TNF maps further toward the telomere within the MHC class III region. The mapping of CSBP close to the $\mathrm{MHC}$ increases the number of functionally related genes within this chromosomal segment. A number of genes that are possibly involved in immune processes have also been identified telomeric of the class I region (Gruen and Weissman 1997), and it is possible that genes functionally linked to genes within the MHC are located within several megabases either side of the complex. Therefore, it would be interesting to investigate any involvement of these genes in autoimmunity or other diseases associated with the MHC. The function of the HSU 09564 serine kinase is not established. It is located at the $3^{\prime}$ end of $\mathrm{p} 21$, which encodes a mediator of p53 function that plays a role in cell cycle regulation.

Of further particular interest is the comparison of this map to the map of mouse chromosome 17. There, the wild-type gene order is cen-H mgi(y)-Tcp11-Tctex-7-Cdkn1(p21)-Glo1-Pim1-Crya-1-Tctex7A-H2ke3-M hc-Tctel-Tel (Lai et al. 1994; Hamvas et al. 1996). Apart from the segment around Cryal that maps to human chromosome 21 , the other genes have been mapped to chromosome $6 \mathrm{p}$. Our data indicate that, in humans, the segment $\mathrm{HMGI}(\mathrm{Y})$ GLO1 is inverted, thus resembling the mouse tcomplex distal inversion in which the gene order is Cen-Pim1-Glo1-Hmgi(y) rather than the wild type (Fig. 5). Also, this segment is considerably closer to the MHC in humans than in mice. Sporadic reports of HLA associations with neural tube defects, spontaneous abortion, and infertility, and observations of transmission distortion and deficits of homozygotes have been reported. Although the findings remain controversial (Kostyu 1994; Jin et al. 1995), this close linkage may explain some of the data. In addition, the region between $\mathrm{Hmgi}(\mathrm{y})$ and $\mathrm{Tcp}-11$ contains the tf locus in mouse and the region between Tcp-11 and Tctex-7B the Hst4 locus and loci for t-complex lethal mutations (Silver 1993a; Foreijt et al. 1994). Human homologs of these loci would then map within 6p21.2-6p21.3.

The gene order in relationship to the centromere for the segment HTCTEX-7-HKE3-MHC resembles the mouse wild type (Fig. 5). The break- 


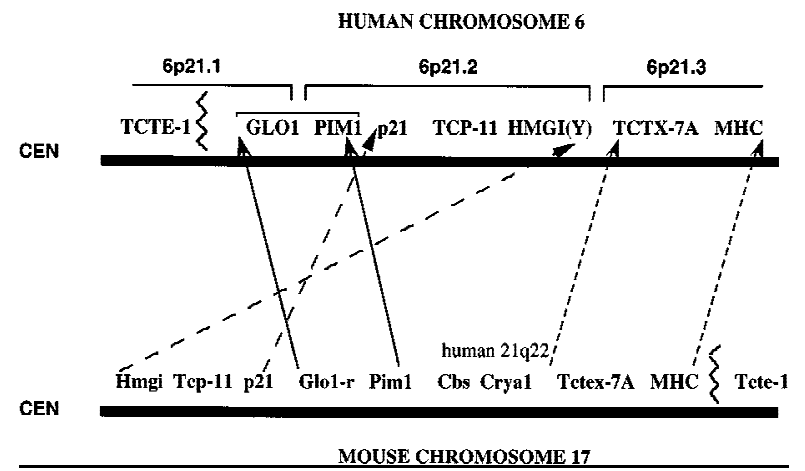

Figure 5 Human-mouse comparative map between the 6p21.1-6p21.3 segment of chromosome 6 and mouse chromosome 17. Blocks of genes are conserved but the relative position and orientations of these blocks are different between the two species.

point of continuous synteny between mice and humans centromeric to the MHC is between the $\mathrm{HMGI}(\mathrm{Y})$ and HTCTEX-7 genes (the position of Bak in mouse is not accurately established) and coincides with chromosomal breakpoints observed in neoplasias. In mouse, the segment Tctex-7A-Cryal containsthe Tctex-8-11 genes, the Ekel- 5 genes, and Rab11b (Lai et al. 1994). Although we did not detect any chromosome 6 cosmid clone for Tctex-11 gene, some of the human homologs of these genes may still map on this chromosome.

When the physical map constructed here is compared to the genetic map, there is good agreement between the genetic distance of D6S291D6S273 reported to be $5 \mathrm{cM}$ and the physical distance, which is $4.2 \mathrm{Mb}$ (as D6S273 maps about 1.7 $\mathrm{Mb}$ away from the end of this contig). The physical mapping of D6S1081 and D6S1051 centromeric of the MHC and of D6S1011 at 6p21.1 allows al so the anchoring of the genetic map generated by Sheffield et al. (1996) to this chromosomal segment.

The PAC clones presented in this study serve as templates for genomic sequencing at the Sanger Centre as part of the effort to completely sequence human chromosome 6 . This effort combined with CDNA selection and exon trapping experiments ( $N$. Tripodis and J. Ragoussis, in prep.) will lead to the construction of a complete transcript map of the 6p21.2-6p21.3 region.

All data presented in this paper have been submitted to GDB (accession no. GDB:6279934).

\section{METHODS}

\section{PCR Primers and Conditions}

PCR primers and conditions were: for D6S291, D6S273,
D6S439 as described by Gyapay et al. (1994); for markers D6S1011, D6S1051, and D6S1081 as described by Sheffield et al. (1995); and for the ESTs FB2A, 02554, 301, and 1324 as described by Pappas et al. (1995). Primers and conditions for markers WI-6620, NIB1566, WI-10190, WI-7311, WI-7940, RPS10-2, and D6S1560 were as described in the Whitehead Institute database, release 11/10/1996 (http://wwwgenome.wi.mit.edu/cgi-bin/contig/phys map). Primers and conditions for the ESTs T54911 and R12494 were as described by Schuler et al. (1996) and for ESTs D6S1535E, D6F304S2E, and D6F310S2E as described by Evans et al. (1996).

Additional primers and conditions are as follows: For HMGI(Y) (CCTTTGCTTCACTTGGTITACCC/GGTAGTCAGGGACAGTCATCAC) $\mathrm{T}_{\text {ann }}=68^{\circ} \mathrm{C}, 1.5 \mathrm{~mm} \mathrm{MgCl}_{2}, 2100-\mathrm{bp}$ product (Friedman et al. (1993); for p21(W AF1) (CTTTCTAGGA G G A G A C A C / G TTC C G CTG CTAATCAAAG) $\mathrm{T}_{\mathrm{ann}}=57.5^{\circ} \mathrm{C}, 1.5 \mathrm{~mm}$, 99-bp product (el-Deiry et al. 1993); for TCTE-1 (B10C:TCTGACAGTTCCGGAGTGC) B10D:AGAGCCTGGTCTCACAAGAG) $\mathrm{T}_{\text {ann }}=62^{\circ} \mathrm{C}, 1.5 \mathrm{~mm}$ $\mathrm{MgCl}_{2}$, 332-bp product (Kwiatkowski et al. 1991); for Motilin (M ot ${ }_{\mathrm{a}}$ :CCCTGACTGTCGCTGTTCC/M ot $_{\mathrm{b}}$ :GTGCACGTGGTCTGAGTGG) $T_{\text {ann }}=62^{\circ} \mathrm{C}, 248$ bp (Gasparini et al. 1994); for glyoxylase (Glo1-L:GGACTGATGGATCACTGTCCC/GIo1R:GCAGCCTCTGAAGGGAACTG) $\mathrm{T}_{\text {ann }}=62^{\circ} \mathrm{C}, 3 \mathrm{~mm} \mathrm{MgCl}_{2}$, 192-bp product; for CSBP (AAAAGGAGAGAAAGTGTA/ TCCACCTGTTCCTCTTTCAT) $48^{\circ} \mathrm{C}, 1.5 \mathrm{~mm} \mathrm{MgCl}_{2}, 547-\mathrm{bp}$ product (McDonnell et al. 1995).

\section{DNA Probes}

The probes and hybridization conditions for tctex 7, tctex 3, and tctex 11 were described previously (Ha et al. 1991). The probes for PIM 1, TCP-11, and ZNF76 were described by Ragoussis et al. (1992), for HKE3 (RPS18) by Hanson and Trowsdale (1991), and for BAK by Kiefer et al. (1995). The probe for D6S29 was described by Hoff et al. (1988).

\section{Genomic Libraries}

YAC libraries The ICI (Anand et al. 1990), CEPH (Albertsen et al. 1990), and ICRF (Larin et al. 1991; clone prefix AM) were screened courtesy of Dr. D. Bentley (Sanger Centre) at Guy's Hospital. Hybridization filters and clones of the human PAC library (Ioannou et al. 1994) were obtained from the MRCHuman Genome Mapping Project-Resource Centre and the Sanger Centre (Hinxton, Cambridge, UK). The BAC clones were isolated by hybridization of filters obtained from $\mathrm{Ge}$ nome Systems (Kim et al. 1996). BAC 6B8, reported to map on 6 p21 (Genome Mapping and Sequencing, Cold Spring Harbor, NY 1994 and Gene Mappers, American Society of Human Genetics Meeting 95) was obtained from Dr. J. Korenberg (UCLA).

YAC 9.2 was subcloned into the cosmid vector Supercos1 after partial $\mathrm{M}$ bol digestion as described previously (Ragoussis and Monaco 1996).

\section{PFGE}

YACs, PACs, and BACs were sized by PFGE. YACs were analyzed as described previously (Ragoussis 1996). The following conditions were used for PACs: $6 \mathrm{~V} / \mathrm{cm}$, pulse time 1-20 sec for $16 \mathrm{hr}$ at $12^{\circ} \mathrm{C}$ in a Bio-Rad DRII apparatus. PFGE of ge- 
nomic DNA was performed as described previously (Ragoussis et al. 1992).

\section{YA C and Bacterial Clone Screening and Characterization}

The chromosome 6 library filters (Nizetic et al. 1994) were screened with Alu PCR probes and whole YAC DNA as described previously (Ragoussis and Monaco 1996). Generation of high-density YAC and cosmid filters and preparation of DNA pools for PCR-based screening was as described previously (Bentley et al. 1992; Cole et al. 1992). YAC end probes were generated by vectorette PCR, and the same technique was applied to PACs, BACs, and cosmids (Ragoussis and Olavesen 1997). Cosmid, PAC, and BAC clone DNA was prepared by use of standard techniques.

\section{YA C Fragmentation}

YACs were fragmented by use of the vector pBCL8.1 (Lewis et al. 1992), and the products were analyzed by the arrayed preparation method (Markie 1995).

\section{Cosmid to PA C Hybridization}

Miniprepped cosmid DNA was digested with HindIII. Then, $10-15 \mathrm{ng}$ of DNA was random oligolabeled with $\left[\alpha^{-32} \mathrm{P}\right] \mathrm{dCTP}$ and incubated for $3 \mathrm{hr}$ at room temperature. With sonicated cosmid vector and sonicated human DNA as competitors, the labeled probe was hybridized to the PAC library for $18 \mathrm{hr}$ at $65^{\circ} \mathrm{C}$ (Gregory 1997).

\section{Fingerprinting and Contig Construction}

Micropreps of clones were performed as described previously (Birnboim and Doly 1979; Gibson and Sulston 1987). Double restriction digest fingerprinting was as first described by Coulson et al. (1986), with the modification of a one-step reaction (Gregory 1997). Briefly, two restriction enzymes (HindIII and Sau3A) and a DNA polymerase (AMV-reverse transcriptase) were employed. The HindIII sites alone were labeled in the first position with $\left[\alpha-{ }^{32} \mathrm{P}\right] \mathrm{dATP}$ before closure with a ddGTP terminator. The bands were separated on a $4 \%$ denaturing polyacrylamide gel. Then, gels were dried to the glass plate and exposed to sensitized autoradiographic film overnight at $-70^{\circ} \mathrm{C}$ in a cassette with intensifying screens and for 3 days at room temperature without screens. Gels were digitized with an Amersham Film Reader. Then, the program Image (Sulston et al. 1989) was used to process and enter the gel. The program FPC (Soderlund and Longden 1996; Gregory 1997) was used to analyze clones. This program has an ACeDB (a Caenorhabditis elegans database) format and uses the probability of coincidence equation adopted from contig 9. Each comparison produces a negative log score. The lower this number, the greater the likelihood that the overlap is genuine.

\section{Chromosome Walking}

End probes from cosmids were generated by digestion of the clones with EcoRI, blotting, and hybridization with Sp6 (for lawrist vector cosmids) or T3 (Supercos vector cosmids) and T7 (lawrist and Supercos) primers (Ragoussis and Olavesen 1997). The bands corresponding to the particular cosmid end were cut out of an LMP gel and used as hybridization probes. Alternatively, end probes were generated by vectorette PCR. The cosmids were digested with EcoRV, Pvull, or Rsal. End primers, specific for the particular vector end were used in combination with the vectorette primers. The same procedure was used for PAC and BAC clones.

\section{FISH}

FISH on metaphase spreads and interphase nuclei was performed as described previously (Olavesen et al. 1995). ECFs were prepared from actively dividing normal male lymphoblasts by use of the technique of Parra and Windle (1993) on slides that had been previously coated with gelatin and polyL-lysine as described by Heiskanen et al. (1994, 1995). Briefly, glass slides were treated for $30 \mathrm{sec}$ in each of $0.2 \mathrm{~N} \mathrm{HCl}$, distilled $\mathrm{H}_{2} \mathrm{O}$, and acetone, and allowed to air dry. Then, they were soaked for $5 \mathrm{~min}$ in $0.15 \%$ gelatin and left to dry overnight at room temperature. The following day, they were soaked twice successively in $0.01 \%$ polyL-lysine and again allowed to dry overnight at room temperature. Then, ECFs were prepared on the coated slides as follows: Actively dividing lymphoblasts were washed and resuspended in PBS at $1.5 \times 10^{5} \mathrm{cell} \mathrm{s} / \mathrm{ml}$. Two $2-\mathrm{ml}$ spots were placed $\sim 1 \mathrm{~cm}$ apart at one end of a horizontally positioned slide and allowed to air dry. Each spot was overlaid with $5 \mathrm{ml}$ of $0.5 \% \mathrm{SDS} / 50 \mathrm{~mm}$ EDTA/200 mm Tris (pH 7.4) and incubated at room temperature for $5 \mathrm{~min}$. The slide was then tilted to an angle of $\sim 60^{\circ}$ to cause the DNA to stream down its length. After air drying at room temperature, the DNA fibers were fixed by treatment in fixative (3:1 methanol/acetic acid) for $3 \mathrm{~min}$. ECF slides were generally prepared 1-3 days before being used for FISH and in the interim were stored at room temperature. FISH on ECFs was performed as for metaphase and interphase nuclei, but with the modification that prehybridization with $50 \times$ (wt/ wt) Cot-1 DNA was for only $8 \mathrm{~min}$.

\section{A CKN O WLEDG MENTS}

This work was supported by grants from the Medical Research Council (G9215293), EEC (GENE-CT93-0075), Wellcome (049873) and the Guy's Hospital Special Trustees. We thank Dr. Karen Artzt and Dr. Young Yeom for the Tctex-7 and Tctex-11 cDNAs; Professor Julie Korenberg for BAC 6B8; Dr. Nigel K. Spurr for the donation of primers for D6S1535E, D6F304S2E, D6F310S2E; Dr. Stepan Beck (Sanger Centre) for his interest in the work; Dr. Mark Olavesen for discussions; and Elisabeth Bentley for technical assistance.

The publication costs of this article were defrayed in part by payment of page charges. This article must therefore be hereby marked "advertisement" in accordance with 18 USC section 1734 solely to indicate this fact.

\section{REFEREN CES}

Abe, K., J.F. Wei, F.S. Wei, Y.C. Hsu, H. Uehara, K. Artzt, and D. Bennett. 1988. Searching for coding sequences in the mammalian genome: $\mathrm{The} \mathrm{H}-2 \mathrm{~K}$ region of the mouse 
MHC is replete with genes expressed in embryos. EMBO J. 7: 3441-3449.

Albertsen, H.M., H. Abderrahim, H.M. Cann, J. Dausset, D. Le Paslier, and D. Cohen. 1990. Construction and characterization of a yeast artificial chromosome library containing seven haploid human genome equivalents. Proc. Natl. Acad. Sci. 87: 4256-4260.

Amadou, C., M.T. Ribouchon, M.G. Mattei, N.A. Jenkins, D.J. Gilvert, N. Copeland, P. Avoustin, and P. Pontarotti. 1995. Localization of new genes and markers to the distal part of the human major histocompatibility complex (MHC) region and comparison with the mouse: New insights on the evolution of mammalian genomes. Genomics 26: 9-20.

Anand, R., J.H. Riley, R. Butler J.C. Smith, and A.F. Markham. 1990. A 3.5 genome equivalent multi access YAC library: Construction, characterization, screening and storage. Nucleic Acids Res. 18: 1951-1956.

Ando, A., Y.Y. Kikuti, H. Kawata, N. Okamoto, T. Imai, T. Eki, K. Yokoyama, E. Soeda, T. Ikemura, K. Abe, and H. Inoko. 1994. Cloning of a new kinesin-related gene located at the centromeric end of the human $\mathrm{MHC}$ region. Immunogenetics 39: 194-200.

Bentley, D.R., C. Todd, J. Collins, J. Holland, I. Dunham, S. Hassock, A. Bankier, and F. Giannelli. 1992. The development and application of automated gridding for efficient screening of yeast and bacterial ordered libraries. Genomics 12: 534-541.

Birnboim, H.C. and J. Doly. 1979. A rapid alkaline extraction procedure for screening recombinant plasmid DNA. Nucleic Acids Res. 7: 1513-1523.

Cole, C.G., K. Patel, J. Shipley, D. Sheer, M. Bobrow, D.R. Bentley, and I. Dunham. 1992. Identification of region-specific yeast artificial chromosomes using pools of Alu element-mediated polymerase chain reaction probes labeled via linear amplification. Genomics 14: 931-938.

Coulson, A., J. Sulston, S. Brenner, and J. Karn. 1986. Toward a physical map of the genome of the nematode Caenorhabditis elegans. Proc. Natl. Acad. Sci. 83: 7821-7825.

Evans, C., M. Bouzyk, S. Cox, D. Warne, S.P. Bryant, and N.K. Spurr. 1996. Chromosomal assignment of 79 cDNAs from a range of human tissues. Genomics 31: 130-134.

Fedele, M., A. Bandiera, G. Chiappetta, S. Battista, G. Viglietto, G. Manfioletti, A. Casamassimi, M. Santoro, V. Giancotti, and A. Fusco. 1996. Human colorectal carcinomas express high levels of high mobility group HMGI(Y) proteins. Cancer Res. 56: 1896-1901.

Foreijt, J., K. Artzt, D. Barlow, R. Hamvas, K.F. Lindahl, M. Lyon, J. Klein, and L.M. Silver. 1994. Mouse chromosome 17. Mamm. Genome 5: 238-258.

Friedman, M., L. Holth, H. Zoghbi, and R. Reeves. 1993. Organization, inducible-expression and chromosome localization of the human HMG-I(Y) nonhistone protein gene. Nucleic Acids Res. 21: 4259-4267.

Gasparini, P., A. Grifa, S. Savasta, I. Merlo, L. Bisceglia, A. Totaro, and L. Zelante. 1994. The motilin gene: Subregional localization, tissue expression, DNA polymorphisms and exclusion as a candidate gene for the HLA-associated immotile cilia syndrome. Hum. Genet. 94: 671-674.

Gibson, T.J. and J.E. Sulston. 1987. Preparation of large numbers of plasmid DNA samples in microtiter plates by the alkaline lysis method. Gene Anal. Techniques 4: 41-44.

Gregory, S. 1997. Contig assembly by fingerprinting. Genome mapping: A practical approach (ed. P.H. Dear). Oxford University Press, Oxford, UK. (In press.)

Gruen, J.R. and S.M. Weissman. 1997. Evolving views of the MHC. Blood (in press).

Gyapay, G., J. Morissette, A. Vignal, C. Dib, C. Fizames, P. Millasseau, S. Marc, G. Bernardi, M. Lathrop, and J. Weissenbach. 1994. The 1993-94 Genethon human genetic linkage map. Nature Genet. 7: 246-249.

Ha, H., C.A. Howard, Y.I. Yeom, K. Abe, H. Uehara, K. Artzt, D. Bennett, A. Cuenda, P. Cohen, V. Buee-Scherrer, and M. Goedert. 1991. Several testis-expressed genes in the mouse t-complex have expression differences between wild-type and t-mutant mice. Dev. Genet. 12: 318-332.

Hamvas, R., Z. Trachtulec, J. Forejt, R.W. Williams, K. Arzt, K. Fischer-Lindahl, and L.M. Silver. 1996. Encyclopedia of the mouse genome $\mathrm{V}$. Mouse chromosome 17. Mamm. Genome 6: S281-S299.

Hanson, I.M. and J. Trowsdale. 1991. Colinearity of novel genes in the class II regions of the MHC in mouse and human. Immunogenetics 34: 5-11.

Heiskanen, M., R. Karhu, E. Hellsten, L. Peltonen, O.P. Kallioniemi, and A. Palotie. 1994. High resolution mapping using fluorescence in situ hybridization to extended DNA fibers prepared from agarose-embedded cells. Biotechniques 17: 928-933.

Heiskanen, M., E. Hellsten, O.P. Kallioniemi, T.P. Makela, K. Alitalo, L. Peltonen, and A. Palotie. 1995. Visual mapping by fiber-FISH. Genomics 30: 31-36.

Hoff, M., Y. Nakamura, T. Holm, S. Gillilan, P.O. O'Connell, M. Leppert, G.M. Lathrop, J.M. Lalouel, and R. White. 1988. Isolation and mapping of a polymorphic DNA sequence (pHHH157) on chromosome 6p [D6S29]. Nucleic Acids Res. 16: 5217.

Ink, B., M. Zornig, B. Baum, N. Hajibagher, C. James, T. Chittenden, and G. Evan. 1997. Human Bak induces cell death in Schizosaccharomyces pombe with morphological changes similar to those with apoptosis in mammalian cells. Mol. Cell. Biol. 17: 2468-2474.

Ioannou, P.A., C.T. Amemiya, J. Garnes, P.M. Kroisel, H. Shizuya, C. Chen, M.A. Batzer, and P.J. de Jong. 1994. A 
new bacteriophage P1-derived vector for the propagation of large human DNA fragments. Nature Genet. 6: 84-89.

Jin, K., H.N. Ho, T.P. Speed, and T.J.R. Gill. 1995. Reproductive failure and the major histocompatibility complex. Am. J. Hum. Genet. 56: 1456-1467.

Johansson, M., C. Dietrich, N. Mandahl, G. Hambraeus, L. Johansson, P. Clausen, F. Mitelman, and S. Heim. 1993. Recombinations of chromosomal bands $6 \mathrm{p} 21$ and $14 q 24$ characterize pulmonary hamartomas. Br. J. Cancer 67: 1236-1241.

Kazmierczak, B., S. Bol, S. Wanschura, S. Bartnitzke, and J. Bullerdiek. 1996. PAC clone containing the HMGI(Y) gene spans the breakpoint of a 6 p21 translocation in a uterine leiomyoma cell line. Genes Chromosomes Cancer 17: 191-193.

Kiefer, M.C., M.J. Brauer, V.C. Wu, J.J. Powers, S.R. Umansky, L.D. Tomei, and P.J. Barr. 1995. Modulation of apoptosis by the widely distributed $\mathrm{Bcl}-2$ homolog Bak. Nature 374: 736-739.

Kim, U.J., B.W. Birren, T. Slepak, V. Mancino, C. Boysen, H.L. Kang, M.I. Simon, and H. Shizuya. 1996. Construction and characterization of a human bacterial artificial chromosome library. Genomics 34: 213-218.

Kostyu, D.D. 1994. HLA: Fertile territory for developmental genes? Crit. Rev. Immunol. 14: 29-59.

Kwiatkowski, T.J., Jr., A.L. Beaudet, B.J. Trask, and H.Y. Zoghbi. 1991. Linkage mapping and fluorescence in situ hybridization of TCTE-1 on human chromosome $6 \mathrm{p}$ : Analysis of dinucleotide polymorphisms on native gels. Genomics 10: 921-926.

Lai, F., L. Stubbs, H. Lehrach, Y. Huang, Y. Yeom, and K. Artzt. 1994. Genomic organization and expressed sequences of the mouse extended H-2K region. Genomics 23: 338-343.

Larin, Z., A. Monaco, and H. Lehrach. 1991. Yeast artificial chromosome libraries containing large inserts from mouse and human DNA. Proc. Natl. Acad. Sci. 88: 4123-4127.

Lee, J.C., J.T. Laydon, P.C. McDonnell, T.F. Gallagher, S. Kumar, D. Green, D. McNulty, M.J. Blumenthal, J.R. Heys, S.W. Landvatter et al. 1994. A protein kinase involved in the regulation of inflammatory cytokine biosynthesis. Nature 372: 739-746.

Lewis, B.C., N.P. Shah, B.S. Braun, and C.T. Denny. 1992. Creation of a yeast artificial chromosome fragmentation vector based on lysine-2. Genome Anal. Techniques Applic. 9: 86-90.

Markie, D. 1995. Arrayed preparation of YAC DNA for pulsed field gel analysis. Nucleic Acids Res. 23: 4526-4527.

McDonnell, P.C., A.G. DiLella, J.C. Lee, and P.R. Young. 1995. Localization of the human stress responsive MAP kinase-like CSAIDs binding protein (CSBP) gene to chromosome 6p21.3/21.2. Genomics 29: 301-302.
Nilbert, M., S. Heim, N. Mandahl, U.-M. Floderus, H. Willen, and F. Mitelman. 1995. Characteristic chromosome abnormalities, including rearrangements of $6 p$, del $(7 q),+12$ and $t(12,14)$ in 44 uterine leiomyomas. Hum. Genet. 85: 605-611.

Nizetic, D., S. Monard, B. Young, F. Cotter, G. Zehetner, and $\mathrm{H}$. Lehrach 1994. Construction of cosmid libraries from flow-sorted human chromosomes 1, 6, 7, 11, 13, and 18 for reference library resources. Mamm. Genome 5: 801-802.

Olavesen, M.G., A.F. Davies, S.J. Broxholme, J. Wixon, G. Senger, D. Nizetic, R.D. Campbell, and J. Ragoussis. 1995. An integrated map of human chromosome $6 \mathrm{p} 23$. Genome Res. 5: 342-358.

Pappas, G.J., M.H. Polymeropoulos, J.M. Boyle, and J.M. Trent. 1995. Regional assignment by hybrid mapping of 36 expressed sequence tags (ESTs) on human chromosome 6. Genomics 25: 124-129.

Parra, I. and B. Windle. 1993. High resolution visual mapping of stretched DNA by fluorescent hybridization. Nature Genet. 5: 17-21.

Ragoussis, J. 1996. Restriction analysis of YACs. Methods Mol. Biol. 54: 69-74.

Ragoussis, J. and A.P. Monaco. 1996. Covering YAC-cloned DNA with phages and cosmids. Methods Mol. Biol.

54: 157-166.

Ragoussis, J. and M. Olavesen. 1997. Generation of probes for chromosome walking. Genome Mapping: A practical approach (ed. P.H. Dear), pp. 255-280. Oxford University Press, Oxford, UK.

Ragoussis, J., G. Senger, I. M ockridge, P. Sanseau, S. Ruddy, K. Dudley, D. Sheer, and J. Trowsdale. 1992. A testis-expressed Zn finger gene (ZNF76) in human 6p21.3 centromeric to the MHC is closely linked to the human homolog of the t-complex gene tcp-11. Genomics 14: $673-679$.

Schuler, G.D., M.S. Boguski, E.A. Stewart, L.D. Stein, G. Gyapay, K. Rice, R.E. White, P. Rodriguez-Tome, A. Aggarwal, E. Bajorek et al. 1996. A gene map of the human genome. Science 274: 540-546.

Sheffield, V.C., J.L. Weber, K.H. Buetow, J.C. Murray, D.A Even, K. Wiles, J.M. Gastier, J.C. Pulido, C. Yandava, S.L. Sunden, G. Mattes, T. Businga, A. McClain, J. Beck, T. Scherpier, J. Gilliam, J. Zhong, and G.M. Duyk. 1995. A collection of tri- and tetranucleotide repeat markers used to generate high quality, high resolution human genome-wide linkage maps. Hum. Mol. Genet. 4: 1837-1844.

Shugart, Y.Y., P. Banerjee, J.A. Knowles, C.A. Lewis, S.G. Jacobson, T.C. Matise, G. Penchaszadeh, T.C. Gilliam, and J. Ott. 1995. Fine genetic mapping of a gene for autosomal recessive retinitis pigmentosa on chromosome $6 \mathrm{p} 21$. Am. J. Hum. Genet. 57: 499-502. 
Silver, L.M. 1993a. Encyclopedia of the mouse genome III. October 1993. Master locus list. Mamm. Genome 4: 2-9.

Silver, L.M. 1993b. The peculiar journey of a selfish chromosome: Mouse t haplotypes and meiotic drive. Trends Genet. 9: 250-254.

Soderlund, C.A. and I. Longden. 1996. FPC. Technical Report SC-01-96. The Sanger Centre, Hinxton, Cambridge, UK.

Strasser, A., S. Whittingham, D.L. Vaux, M.L. Bath, J.M. Adams, S. Cory, and A.W. Harris. 1991. Enforced BCL2 expression in B-lymphoid cells prolongs antibody responses and elicits autoimmune disease. Proc. Natl. Acad. Sci. 88: 8661-8665.

Sulston, J., F. Mallett, R. Durbin, and T. Horsnell. 1989. Image analysis of restriction enzyme fingerprint autoradiograms. Comput. Appl. Biosci. 5: 101-106.

Xiao, S., M.L. Lux, R. Reeves, T.J. Hudson, and J.A. Fletcher. 1997. $\mathrm{HMGI}(\mathrm{Y})$ activation by chromosome $6 \mathrm{p} 21$ rearrangements in multilineage mesenchymal cells from pulmonary hamartoma. Am. J. Pathol. 150: 901-910.

Yeom, Y.I., K. Abe, and K. Artzt. 1992. Evolution of the mouse $\mathrm{H}-2 \mathrm{~K}$ region: $\mathrm{A}$ hot spot of mutation associated with genes transcribed in embryos and/or germ cells. Genetics 130: 629-638.

Received July 15, 1997; accepted in revised form April 13, 1998. 


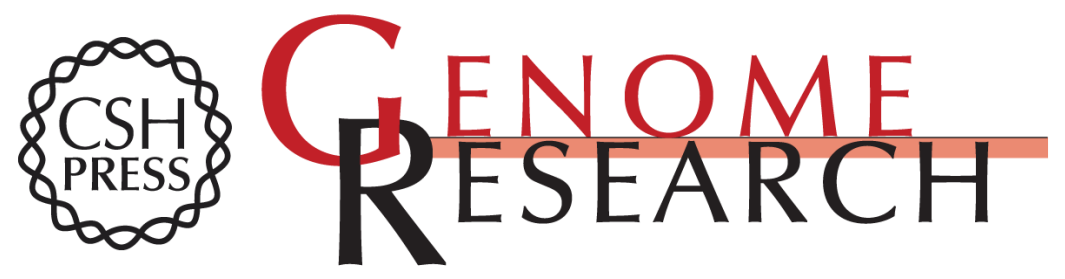

\section{Physical Map of Human 6p21.2-6p21.3: Region Flanking the Centromeric End of the Major Histocompatibility Complex}

Nicos Tripodis, Ruth Mason, Sean J. Humphray, et al.

Genome Res. 1998 8: 631-643

Access the most recent version at doi:10.1101/gr.8.6.631

References This article cites 50 articles, 9 of which can be accessed free at:

http://genome.cshlp.org/content/8/6/631.full.html\#ref-list-1

\section{License}

Email Alerting Receive free email alerts when new articles cite this article - sign up in the box at the Service top right corner of the article or click here.

\section{Affordable, Accurate Sequencing.}

